\title{
Maternal and perinatal outcomes in women with first trimester vaginal bleeding
}

\author{
K. Suganya, Latha Maheswari Subbarayan*
}

Department of Obstetrics and Gynecology, PSG IMSR Hospitals, Coimbatore, Tamil Nadu, India

Received: 26 August 2019

Accepted: 30 September 2019

\section{*Correspondence:}

Dr. Latha Maheswari Subbarayan,

E-mail: lathamaheshwari@gmail.com

Copyright: ( $)$ the author(s), publisher and licensee Medip Academy. This is an open-access article distributed under the terms of the Creative Commons Attribution Non-Commercial License, which permits unrestricted non-commercial use, distribution, and reproduction in any medium, provided the original work is properly cited.

\begin{abstract}
Background: First trimester bleeding is one of the common complications during pregnancy which affects almost 16$25 \%$ of all pregnancies. To evaluate and ascertain the adverse maternal and perinatal outcomes in pregnant women presenting with first trimester vaginal bleeding.

Methods: Prospective case-control study. A case control study involving 60 pregnant women with vaginal bleeding in the first 13 weeks +6 days of gestational age with 60 matched controls. The study period was from March 2015 to March 2016 and conducted at PSG Institute of Medical Sciences and Research, Coimbatore, Tamil Nadu.

Results: The complications seen in the study group were: first trimester abortion (16.7\%), second trimester abortion $(6.7 \%)$, preterm labour (25\%), abruption (6.7\%), neonatal intensive care admission (25\%), ectopic (6.7\%), IUGR (10\%), IUD (1.7\%) and PROM (8.3\%). When compared with the parity matched controls there was statistically significant increase in first and second trimester abortions, preterm labour, abruption, NICU admission and ectopic pregnancy whereas there was no significant difference between the two groups with regard to intrauterine growth restriction (IUGR) and intrauterine death (IUD).

Conclusions: Women with first trimester vaginal bleeding had several adverse outcomes in both the mother and the fetus, and it is very important to explain about the possibility of these outcomes and ensure proper follow up with close antenatal surveillance.
\end{abstract}

Keywords: Adverse maternal outcome, Adverse fetal outcome, First trimester threatened abortion, First trimester vaginal bleeding, Sub chorionic hematoma, Threatened miscarriage

\section{INTRODUCTION}

First trimester bleeding is one of the common complications during pregnancy which affects almost 16$25 \%$ of all pregnancies. ${ }^{1,2}$

The presumptive symptom of threatened miscarriage is the history of vaginal bleeding in early pregnancy with closed cervix. Meta-analysis indicates that vaginal bleeding increases the risk of pregnancy complications by twofold. ${ }^{3}$ Vaginal bleeding may herald the initiation of spontaneous abortion, or it can be a sign of implantation of pregnancy, or it can be a pathological sign indicating gestational trophoblastic disease or ectopic pregnancy.

Vaginal bleeding during early pregnancy needs further evaluation to identify normal or abnormal pregnancy or any pathological condition which requires immediate intervention. ${ }^{4,5}$ It is hypothesized that vaginal bleeding in first trimester may be an indication of an underlying placental dysfunction, which may manifest later on with adverse outcomes like first or second trimester abortion, 
pre-eclampsia, preterm delivery, premature rupture of membranes, intrauterine growth restrictions and intra uterine death. ${ }^{6}$

This study aims to evaluate maternal and perinatal outcomes in women with first trimester vaginal bleeding.

\section{METHODS}

This study was approved by the institutional Human Ethics Committee (IHEC), PSG Institute of Medical Sciences and Research, which has been recognized by the Strategic Initiative for Developing Capacity in Ethical Review (SIDNER). This study was conducted among 120 subjects in PSG Hospitals. Among the 120 patients studied, 60 pregnant women who had first trimester vaginal bleeding were compared with 60 matched controls, over one year from March 2015 to March 2016.

All pregnant women who attended antenatal clinic with first trimester vaginal bleeding $(<12$ weeks $)$ were included in this study. Women with multiple pregnancies, bad obstetric history, congenital uterine abnormality, known case of any bleeding disorders, chronic medical complications including diabetes and hypertension were excluded from this study. Informed consent was obtained and they were put under surveillance till delivery. Ultrasonography was performed for all these women as routine and serum beta-HCG was done in indicated cases. They were followed up once a month for the first six months, once a fortnight during seventh and eighth month and weekly during the last month of pregnancy. The data collected was analyzed and significant outcomes were reported.

\section{Statistical analysis}

Data collected from the patients were initially entered into Microsoft Excel-sheets analyzed using SPSS. Pearson's chi-square was used to compare the association between the first trimester vaginal bleeding and the adverse maternal and fetal outcomes. A predictive value of less than 0.05 was taken as statistically significant.

\section{RESULTS}

In this study 120 women were included (those who met the inclusion criteria) among which 60 women were in control group and 60 in study group. The study and control group were selected based on the following demographic characteristics. The demographic data in each of these groups are represented in Table 1. There was no statistically significant difference between the two groups with respect to the baseline characteristics as age, height, weight, BMI and parity.

The maternal and perinatal outcomes of the women with first trimester vaginal bleeding were compared among the study and the control groups and represented in Table 2 . There was significant difference between two groups in the following primary outcomes such as first and second trimester abortions, pre-term labor, abruption, NICU admission, ectopic pregnancy and nil complications. The results were statistically significant.

Table 1: Demographic characteristics in women with first trimester threatened miscarriage in case and control group.

\begin{tabular}{|llll|}
\hline Parameters & Study $(\mathrm{n}=60)$ & Control $(\mathrm{n}=60)$ & P value \\
\hline Age $($ years $)$ & $25.7 \pm 2.88$ & $26.10 \pm 2.77$ & 0.99 \\
\hline Height $(\mathrm{m})$ & $1.53 \pm 0.08$ & $1.56 \pm 0.09$ & 0.89 \\
\hline Weight $(\mathrm{kg})$ & $73.42=/-5.88$ & $72.11 \pm 6.16$ & 0.44 \\
\hline BMI $\left(\mathrm{kg} / \mathrm{m}^{\wedge} 2\right)$ & $29.38 \pm 1.2$ & $29.12 \pm 2.3$ & 0.63 \\
\hline \multirow{2}{*}{ Parity } & Primiparous: $18 / 60$ & Primiparous: $12 / 60$ & 0.61 \\
\hline
\end{tabular}

Table 2: Maternal and perinatal outcomes of the women with first trimester.

\begin{tabular}{|llll|}
\hline Outcomes & Study $(\mathrm{n}=60)$ & Control $(\mathrm{n}=60)$ & P value \\
\hline $1^{\text {st }}$ trimester abortion & $16.7 \%(10 / 60)$ & $3.3 \%(2 / 60)$ & 0.015 \\
\hline $2^{\text {nd }}$ trimester abortion & $6.7 \%(4 / 60)$ & - & 0.042 \\
\hline Preterm labor & $25 \%(15 / 60)$ & $6.7 \%(4 / 60)$ & 0.006 \\
\hline Abruption & $6.7 \%(4 / 60)$ & - & 0.042 \\
\hline NICU admission & $25 \%$ & $6.7 \%$ & 0.006 \\
\hline No complications & $16.7 \%$ & $83.3 \%$ & 0.00 \\
\hline Ectopic pregnancy & $6.7 \%(4 / 60)$ & - & 0.042 \\
\hline
\end{tabular}


Table 3: Secondary outcomes.

\begin{tabular}{|llll|}
\hline Parameters & Study $(\mathrm{n}=60)$ & Control $(\mathrm{n}=60)$ & P value \\
\hline IUGR & $10 \%(6 / 60)$ & $3.3 \%(2 / 60)$ & 0.143 \\
\hline IUD & $1.7 \%(1 / 60)$ & NIL & 0.315 \\
\hline APGAR $<7$ & $10 \%(6 / 60)$ & $3.3 \%(2 / 60)$ & 0.143 \\
\hline PROM & $8.3 \%(5 / 60)$ & $5 \%(3 / 60)$ & 0.464 \\
\hline
\end{tabular}

The secondary outcomes such as intra-uterine growth restriction (IUGR), intrauterine fetal demise (IUD), premature rupture of membranes (PROM) and neonatal APGAR score of $<7$ were not statistically significant (Table 3).

\section{DISCUSSION}

Vaginal bleeding is one of the most common and alarming early pregnancy symptoms. The aim of this study was to evaluate the risk factors associated with first trimester bleeding and the various adverse outcomes. Several studies had reported the association between vaginal bleeding in first trimester and the adverse maternal and perinatal outcomes which include abortion, preterm labor, low birth weight, intra uterine growth restriction. Most of these studies were retrospective.

This study was a randomized, prospective case - control study.

In this study, the amount of blood loss and its effects in pregnancy outcomes was also evaluated as it is important in predicting the risk of miscarriage. In the study group 8 among 10 women who had a first trimester miscarriage had heavy bleeding (quantified by the pictorial charts).

From this study it is clear that more than $80 \%$ of the women with first trimester miscarriage had heavy bleeding. Further analysis also suggests that pain associated with this heavy bleeding is also significant.

Whereas women with spotting per vaginum had comparatively good outcome. This result is similar to other studies which also indicate greater risk with heavy bleeding. ${ }^{7}$

This study showed that there was statistically significant difference in the first and second trimester miscarriage between the study and control groups. Many other studies have also documented that the rate of first and second trimester abortions in women with first trimester vaginal bleeding were approximately $20 \%$ and $18 \%$ respectively..$^{8-10}$

Preterm labor and delivery are one of the most leading cause of neonatal death. This study showed that women with first trimester bleeding have significantly increased risk of having preterm labor in study group (25\%) when compared to control group (6.7\%) and premature rupture of membranes in study group $(8.3 \%)$ when compared to control group (5\%). This result is similar to the previous studies. ${ }^{10,11}$

A study by Saraswat et al which was a meta-analysis also suggested a higher incidence of preterm labor and premature rupture of membranes, but a similar study done by Strobino et al did not show any significant association between first trimester bleeding and preterm labour. ${ }^{12,13}$ Placental abruption occurs in approximately $2 \%$ of all the pregnancies and the most common cause is first trimester bleeding. The hematoma that collects in between the chorionic plate and the uterus gradually increases in size and separates the placenta and causes heavy bleeding and eventually leads to abruption.

In this study the abruption rate in the study group was $6.7 \%$ whereas there was no abruption in control group. Hence this study suggests that women with threatened miscarriage have a very high risk of abruption hence close monitoring in very essential. The results of this study are similar with the findings of Weiss et al and Ananth et al, which also showed a significant incidence in abruption in women associated with first trimester bleeding, but on the contrary studies done by Wijesiriwardana and Jihn's et al did not show any significance in the relationship between the two. ${ }^{14-16}$

The incidence of IUGR (10\%) and IUD (1.7\%) in the study group was not statistically different from the control group $(3.3 \%$ and $0 \%$ respectively). A similar outcome was seen in a study done by Amirkahani $\mathrm{Z}$ which also had an incidence of $1.7 \%$ (IUD) and $12 \%$ (IUGR) in women with first trimester vaginal bleeding. ${ }^{8}$

To our surprise some women also had a positive outcome by delivering a live baby without any complications such as preterm labour, placental abnormalities, PROM, IUD, NICU admissions or intra uterine growth restriction.

In this study about $16.7 \%$ of women in the study group had a good outcome with none of the above-mentioned complications when compared with the control group where $83.3 \%$ women had no complications. This result was statistically significant.

This result suggests that women who had first trimester threatened miscarriage, if given proper antenatal care and by routine ultrasound and regular follow up and specific 
management, could deliver a live term baby without any complications.

\section{CONCLUSION}

Considering the outcome of this study, women with first trimester vaginal bleeding had several adverse outcomes in both the mother and the fetus, and it is very important to explain about these outcomes and ensure regular close care antenatal surveillance.

Further, intervention by the clinicians has an important role in not only helping the women to continue the pregnancy but also help in reducing the maternal and fetal complications in high risk pregnancies. Hence precise treatment and planning is essential.

Funding: No funding sources

Conflict of interest: None declared

Ethical approval: The study was approved by the Institutional Ethics Committee

\section{REFERENCES}

1. Farrell T, Owen P. The significance of extra chorionic membrane separation in threatened miscarriage. Br J Obstet Gynaecol. 1996;103:926-8.

2. Bowe $\mathrm{P}$, Murphy $\mathrm{H}$. Complications of pregnancy following threatened abortion. Irish J Med Sci. 1987; 156:328-9.

3. Ananth C, Savitz D. Vaginal bleeding and adverse reproductive outcomes: a meta-analysis. Paediatric Perinatal Epidemiol. 1994;8:62-78.

4. Snell BJ. Assessment and management of bleeding in the first trimester of pregnancy. J Midwifery Women's Health. 2009;54:483-91.

5. Dogra V, Paspulati RM, Bhatt S. First trimester bleeding evaluation. Ultrasound Q. 2005;21:69-85.

6. Weiss JL, Malone ED, Vidaver J. Threatened miscarriage: a risk factor for poor pregnancy outcome, a population-based screening study. Am J Obstet Gynecol. 2004;190:745-50.

7. Yang J, Savitz DA, Dole N. Predictors of vaginal bleeding during the first two trimesters of pregnancy. Paediatr Peri Epidemiol. 2005;19(4):276-83.
8. Amirkhani Z, Akhlaghdoust M, Abedian M, Salehi GR, Zarbati N, Mogharehabed M, et al. Maternal and perinatal outcomes in pregnant women with first trimester vaginal bleeding. J Family Reprod Health. 2013;7(2):57.

9. Agrawal S, Khoiwal S, Kumar J, Agarwa R. Predicting adverse maternal and perinatal outcomes after threatened miscarriage. Open J Obstet Gynaecol. 2013;2014.

10. Ishtiaq S, Qadir T, Ali HS. Maternal and perinatal outcome in threatened miscarriage in first trimester. ISRA Med J. 2014;6(3):169-72.

11. Bennett G, Bromley B, Lieberman E, Benacerraf BR. Sub chorionic hemorrhage in first-trimester pregnancies: prediction of pregnancy outcome with sonography. 1996;200(3):803-6.

12. Saraswat 1, Bhattacharya S, Maheshwari A, Bhattacharya S. Maternal and perinatal outcome in women with threatened miscarriage in the first trimester: a systematic review. BJOG. 2010;117:24557.

13. Strobino B, Pantel-Silverman J. Gestational vaginal bleeding and pregnancy outcome. Am J Epidemiol. 1989;129(4):806-15.

14. Weiss JL, Malone FD, Vidaver J. Threatened abortion: a risk factor for poor pregnancy outcome, a population-based screening study. Am J Obstet Gynecol. 2004;190(3):745-50.

15. Ananth CV, Oyelese Y, Prasad V. Evidence of placental abruption as a chronic process: associations with vaginal bleeding early in pregnancy and placental lesions. Eur J Obstet Gynecol Reprod Biol. 2006;128(1-2):15-21.

16. Wijesiriwardana A, Bhattacharya S, Shetty A. Obstetric outcome in women with threatened miscarriage in the first trimester. Obstet Gynecol. 2006;107(3):557-62.

Cite this article as: Suganya K, Subbarayan LM. Maternal and perinatal outcomes in women with first trimester vaginal bleeding. Int J Reprod Contracept Obstet Gynecol 2019;8:4320-3. 